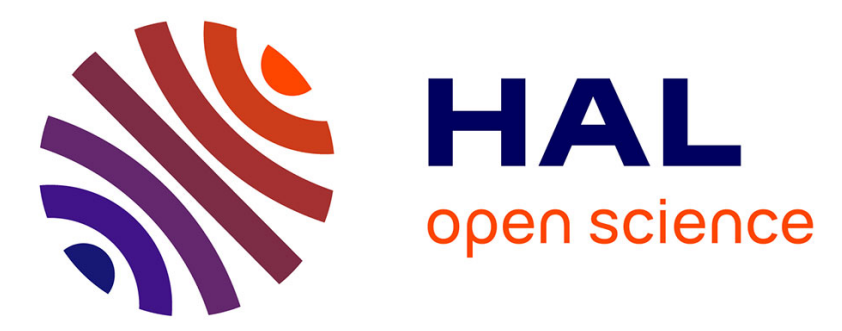

\title{
Magnetic and structural properties of iron nitride thin films obtained by argon-nitrogen reactive radio-frequency sputtering
}

Jean-François Bobo, H. Chatbi, M. Vergnat, L. Hennet, O. Lenoble, Ph. Bauer, M. Piecuch

\section{To cite this version:}

Jean-François Bobo, H. Chatbi, M. Vergnat, L. Hennet, O. Lenoble, et al.. Magnetic and structural properties of iron nitride thin films obtained by argon-nitrogen reactive radio-frequency sputtering. Journal of Applied Physics, 1995, 77 (10), pp.5309-5313. 10.1063/1.359286 . hal-02113424

\section{HAL Id: hal-02113424 https://hal.science/hal-02113424}

Submitted on 28 Apr 2019

HAL is a multi-disciplinary open access archive for the deposit and dissemination of scientific research documents, whether they are published or not. The documents may come from teaching and research institutions in France or abroad, or from public or private research centers.
L'archive ouverte pluridisciplinaire HAL, est destinée au dépôt et à la diffusion de documents scientifiques de niveau recherche, publiés ou non, émanant des établissements d'enseignement et de recherche français ou étrangers, des laboratoires publics ou privés. 


\title{
Magnetic and structural properties of Iron nitride thin films obtained by argon-nitrogen reactive radio-frequency sputtering
}

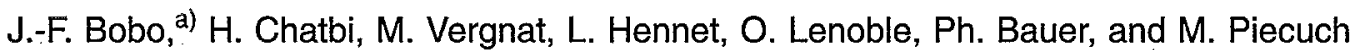 \\ Laboratoire de Métallurgie Physique et Science des Matériaux, URA au CNRS No. 155, Université \\ Henry Poincaré, BP 239, 54506 Vandoeuvre-lès-Nancy Cedex, France
}

(Received 21 November 1994; accepted for publication 6 February 1995)

\begin{abstract}
We have prepared iron nitride thin films by reactive if sputtering of an iron target in an argon-nitrogen plasma. The films present a wide variety of structures and compositions: $\alpha$ expanded bcc iron, amorphous $\mathrm{Fe}_{1-x}-\mathrm{N}_{x}, \gamma^{\prime}-\mathrm{Fe}_{4} \mathrm{~N}, \epsilon-\mathrm{Fe}_{2-3} \mathrm{~N}$, and $\zeta-\mathrm{Fe}_{2} \mathrm{~N}$. Evolutions of the crystallographic structures and of the magnetic properties of the obtained phases are discussed versus the nitrogen concentration in the gaseous flow and the substrate temperature during deposition. (c) 1995 American Institute of Physics.
\end{abstract}

\section{INTRODUCTION}

$\mathrm{Fe}-\mathrm{N}$ thin films have attracted considerable attention because they are potential candidates for magnetic recording with their large saturation magnetization and their good corrosion resistance. ${ }^{1}$ It has even been demonstrated that saturation magnetization can be larger than the bulk iron one for low nitrogen contents. ${ }^{2}$ The origin of the enhanced magnetic moment could occur from the metastable $\alpha^{\prime \prime} \mathrm{Fe}_{16} \mathrm{~N}_{2}$ phase or from an expanded bcc FeN structure which is also called $\alpha$ FeN.

Several ways for obtaining iron nitride films have been investigated.

(1) Thermal evaporation with a nitrogen partial pressure (either atomic or molecular nitrogen): such a technique is not the most suitable for the preparation of nitrogen-rich Fe-N alloys, but several groups have successfully obtained $\alpha, \alpha^{\prime \prime}$, or $\gamma^{\prime}$ FeN phases. ${ }^{3,4}$ Let us also notice that molecular beam epitaxy growth of $\alpha^{\prime \prime}$ phase is possible, according to Komuro et al. ${ }^{5}$

(2) Reactive sputtering: contrary to thermal evaporation, reactive sputtering allows one to obtain a wide variety of iron nitrides. As underlined by Takahashi et al. ${ }^{6}$ or Gao et al., ${ }^{7}$ the use of adapted seed layers like (100) iron buffer grown on (100) MgO substrate accompanied with thermal annealing leads to $\alpha$ or $\alpha^{\prime \prime}$ phases. The role of this thermal treatment is to reorder nitrogen atoms in the iron expanded lattice. From another point of view, Xiao and Chien ${ }^{8}$ have sputtered all the iron nitrides (except $\alpha^{\prime \prime}$ ) on unheated substrates and without any other treatment using ammonia reactive gas. These last authors suggest $\mathrm{NH}_{3}$ is the best solution for growing single phase iron nitrides.

Our present work is devoted to preparation and study of as-deposited sputtered Fe-N films. They have been prepared in a large range of nitrogen partial pressures and with substrate temperatures ranging from $\approx 40^{\circ} \mathrm{C}$ (unheated) up to $600{ }^{\circ} \mathrm{C}$. The different structural phases have been identified by $\mathrm{x}$-ray diffraction and Mössbauer spectroscopy. These results are correlated with bulk magnetization measurements.

\footnotetext{
a) Author to whom correspondence should be addressed: LMPSM-URA 155, Université de Nancy I, BP 239, 54506 Vandœuvre Cedex, France; FAX: (33) 83.91.20.83; Electronic mail: bobo@1ps.u-nancy.fr
}

\section{EXPERIMENTAL PROCEDURES}

Iron nitride films are deposited on microelectronic-grade (100) Si wafers in an Alcatel SCM 650 automated sputtering setup. The base pressure is $7 \times 10^{-7} \mathrm{mb}$ and the working pressure $3 \times 10^{-3} \mathrm{mb}$. The iron target is $500 \mathrm{~W}$ rf polarized $\left(\approx 6.3 \mathrm{~W} / \mathrm{cm}^{2}\right)$ and the deposition rate is close to $3 \AA \AA \mathrm{s}$ if substrates are located $10 \mathrm{~cm}$ above the target. Such sputtering conditions have been chosen because they provide high density and low roughness (110) textured Fe films in pure argon plasma sputtering. ${ }^{9}$ Note that this experimental context leads to a spontaneous (110) $\alpha \mathrm{Fe}$ dense plane growth.

Nitrides have been obtained by introducing several controlled amounts of nitrogen in the main argon atmosphere, keeping the total pressure equal to the previous value of $3 \times 10^{-3} \mathrm{mb}$. The nitrogen percentage $x_{\mathrm{N}_{2}}$ in the gaseous flow ranges from $0 \%$ to $40 \%$. The total thickness of each sample was $1250 \pm 50 \AA$. The substrate's temperature is varied between room temperature (unheated substrate) and $600{ }^{\circ} \mathrm{C}$.

These- samples were structurally characterized by $\mathrm{X}$-ray diffraction (XRD) with a $K_{\beta}$-filtered Co $K_{\alpha}$ radiation (1.78892 $\AA$ ) on a $\theta / 2 \theta$ Philips goniometer operating with a Raytech position sensitive detector. Crystallographic phases were deduced from comparison of experimental diffraction profiles with standard ones (JCPDS data). Some uncertainty is left for the determination of $\epsilon-\mathrm{Fe}_{2-3} \mathrm{~N}$ phase because of the relatively large variations of its crystalline parameters among the compositional domain where it exists.

Local magnetic properties have been investigated by conversion electron Mössbauer spectroscopy (CEMS). Mössbauer spectra were recorded at room temperature in the backscattering mode with a $\mathrm{He}\left(5 \% \mathrm{CH}_{4}\right)$ gas flow proportional counter. This allows a nondestructive study with a sampling depth of about $2500 \AA$, encompassing therefore the whole thickness of iron nitride films: The source drive and data storage were of usual design. The ${ }^{57} \mathrm{Fe}$ hyperfine pattern was fitted with standard routines where Lorentzian line shapes were assumed.

Bulk magnetization measurements have been performed with either a vibrating sample magnetometer (VSM) or a quantum design superconducting quantum interference device down to $5 \mathrm{~K}$. Room temperature Kerr rotation cycles have also been performed in both longitudinal and polar ge- 


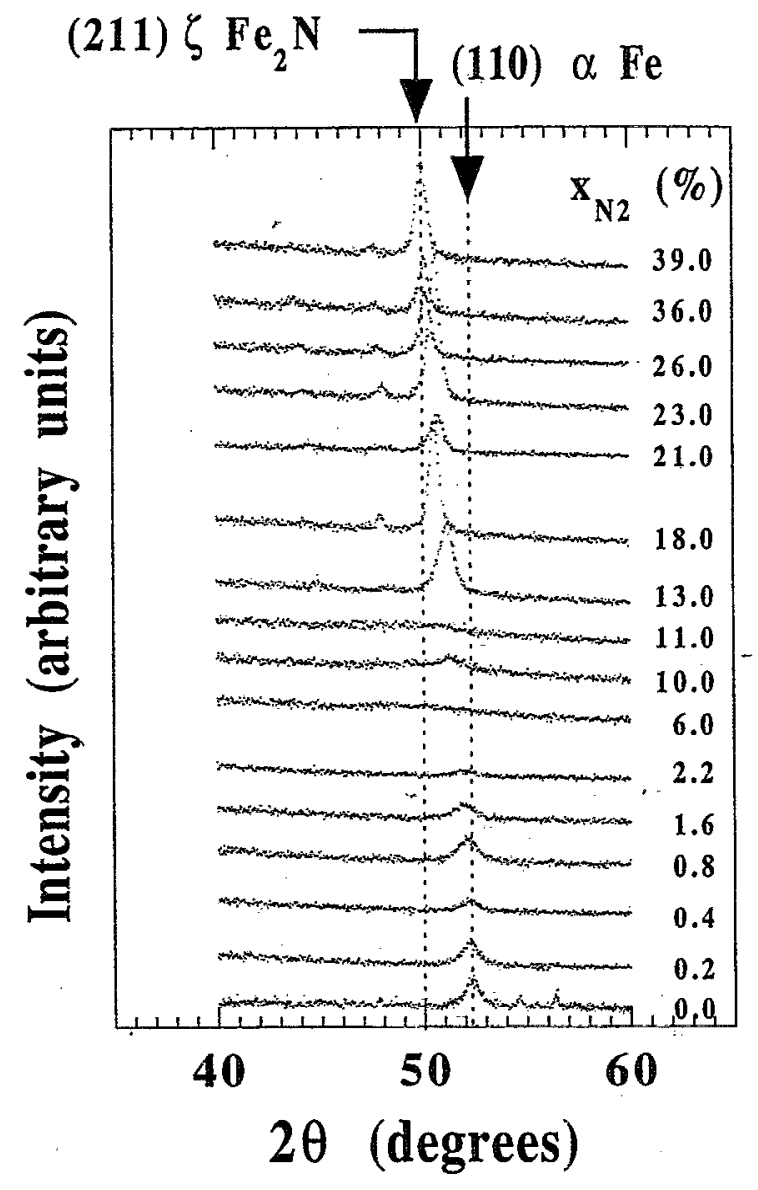

FIG. 1. XRD experiments performed on the series of Fe- $\mathrm{N}$ films deposited at room temperature as a function of the nitrogen concentration in the plasma.

ometries, they give similar results to the VSM ones but faster and with a better accuracy for determining coercive fields.

\section{RESULTS}

\section{A. Crystallographic structure}

Structural properties of the films deposited on unheated substrates are illustrated in Fig. 1 which represents the evolution of XRD peaks as a function of the nitrogen partial pressure in the plasma. These results can be summarized as follows.

(1) At very low nitrogen concentrations, films only show the usual (110) diffraction peak of the bcc iron structure but with a small shift towards low angles. We attribute this to a lattice expansion of bcc Fe which is called $\alpha$ FeN. Lattice expansion reaches up to $0.7 \%$.

(2) With increasing $\mathrm{N}_{2}$ concentration, diffraction peaks become broader: it is the signature of an amorphous FeN alloy. This is the first observation, to our knowledge, of an amorphous iron nitride phase.

(3) For $x_{\mathrm{N}_{2}}$ equal to 0.08 , an XRD peak appears at $51.4^{\circ}$, it could be the (111) peak of hexagonal $\epsilon-\mathrm{Fe}_{2-3} \mathrm{~N}$ phase, coexisting with amorphous Fe-N.
(4) For higher values of $x_{N_{2}}\left(0.18 \leqslant x_{N_{2}} \leqslant 0.24\right)$, the (101) peak of hexagonal $\epsilon \mathrm{Fe}_{3} \mathrm{~N}$ phase is observed.

(5) Finally, for $x_{\mathrm{N}_{2}} \geqslant 0.26$, the diffraction spectrum only shows the (211) peak of the orthorhombic $\zeta-\mathrm{Fe}_{2} \mathrm{~N}$ phase.

The samples deposited on heated substrates were better crystallized. From a more general point of view, increasing the substrate temperature from 300 to $600^{\circ} \mathrm{C}$ leads to a transformation into $\gamma^{\prime}-\mathrm{Fe}_{4} \mathrm{~N}$ of all the iron nitrides which could be obtained at room temperature. This behavior is easy to explain as the $\gamma^{\prime}$ phase is the most stable in this range of temperatures. Of course, any combination of these situations could be found for intermediate temperatures.

Finally, XRD indicates the presence of various iron nitride structures in our films. However, because of grain size or texture effects, we cannot accurately estimate their proportions in the samples. A summary of the identified phases versus substrate temperature $\left(T_{S}\right)$ and nitrogen atomic ratio $\left(x_{\mathrm{N}_{2}}\right)$ is given in Table $\mathrm{I}$.

\section{B. Mössbauer spectroscopy}

Some experimental and calculated CEMS spectra are displayed in Fig. 2. They are representative of the evolution versus nitrogen concentration of the plasma $\left(x_{\mathrm{N}_{2}}\right)$ and substrate temperature $\left(T_{S}\right)$. The spectra analysis of crystallized phases was carried out mostly with superimposed discrete six line patterns (magnetic phases) and/or a quadrupole split doublet (nonmagnetic phases). For most of the magnetic nitrides, the intensity behavior within the sextet indicates inplane magnetization.

Spectra of amorphous magnetic iron nitrides do not exhibit the discrete sextet of crystallized magnetic phases but a broad distribution, they have been analyzed with a hyperfine field distribution according to the histogram method.

So, magnetic components have been attributed, respectively, to pure bcc iron, to iron atoms with a slightly shifted hyperfine field ( $\alpha$ expanded bce iron); to amorphous magnetic $\mathrm{Fe}-\mathrm{N}$, to $\gamma^{\prime}-\mathrm{Fe}_{4} \mathrm{~N}$ multisite compound, and to $\epsilon-\mathrm{Fe}_{2-3} \mathrm{~N}$. According to their isomer shifts, paramagnetic components are found to be relevant to $\zeta-\mathrm{Fe}_{2} \mathrm{~N}$ species.

CEMS results have been found to be coherent with XRD along the main lines of our work with evidence for $\gamma^{\prime}-\mathrm{Fe}_{4} \mathrm{~N}$ at high $T_{S}, \zeta-\mathrm{Fe}_{2} \mathrm{~N}$ for high $x_{\mathrm{N}_{2}}$, amorphous $\mathrm{Fe}-\mathrm{N}$ for $T_{S}$ close to room temperature, and $x_{\mathrm{N}_{2}} \approx 5 \%$. However, some discrepancies exist for intermediate $T_{S}$ and $x_{\mathrm{N}_{2}}$. In fact, while Mössbauer spectroscopy detects all the iron environments, only the best crystallized phases are revealed by XRD when a mixture of various nitrides sets in.

Let us also notice that a small paramagnetic contribution is found in amorphous phase. This is due to the existence of nonmagnetic iron sites in amorphous Fe- $\mathrm{N}$. Contrary to $\mathrm{XRD}$, it has been possible to estimate the atomic abundances of the various phases from the analysis of the spectra. Some of these results are quoted in Fig. 2. 
TABLE I. "Phase diagram" of sputtered iron nitrides. Nitrogen to argon ratio increases along horizontal lines and deposition temperature increases along columns.

\begin{tabular}{|c|c|c|c|c|c|c|}
\hline $600^{\circ} \mathrm{C}$ & $\alpha$-Fe & $\gamma^{\prime}-\mathrm{Fe}_{4} \mathrm{~N}$ & $\gamma^{\prime}-\mathrm{Fe}_{4} \mathrm{~N}$ & $\gamma^{\prime}-\mathrm{Fe}_{4} \mathrm{~N}$ & $\gamma^{\prime}-\mathrm{Fe}_{4} \mathrm{~N}$ & $\gamma^{\prime}-\mathrm{Fe}_{4} \mathrm{~N}$ \\
\hline $400^{\circ} \mathrm{C}$ & $\alpha-\mathrm{Fe}$ & $\begin{array}{l}\alpha-\mathrm{Fe} \\
\gamma^{\prime}-\mathrm{Fe}_{4} \mathrm{~N} \\
\epsilon-\mathrm{Fe}_{2-3} \mathrm{~N}\end{array}$ & $\begin{array}{l}\alpha-\mathrm{Fe} \\
\gamma^{\prime}-\mathrm{Fe}_{4} \mathrm{~N} \\
\epsilon-\mathrm{Fe}_{2-3} \mathrm{~N}\end{array}$ & $\begin{array}{l}\gamma^{\prime}-\mathrm{Fe}_{4} \mathrm{~N} \\
\epsilon-\mathrm{Fe}_{2-3} \mathrm{~N}\end{array}$ & $\gamma^{\prime}-\mathrm{Fe}_{4} \mathrm{~N}$ & \\
\hline $200^{\circ} \mathrm{C}$ & $\alpha-\mathrm{Fe}$ & $\begin{array}{l}\alpha-\mathrm{Fe} \\
\gamma^{\prime}-\mathrm{Fe}_{4} \mathrm{~N} \\
\epsilon-\mathrm{Fe}_{2-3} \mathrm{~N}\end{array}$ & $\begin{array}{l}\gamma^{\prime}-\mathrm{Fe}_{4} \mathrm{~N} \\
\epsilon-\mathrm{Fe}_{2-3} \mathrm{~N} \\
\text { Amorphous }\end{array}$ & $\begin{array}{l}\gamma^{\prime}-\mathrm{Fe}_{4} \mathrm{~N} \\
\epsilon-\mathrm{Fe}_{2-3} \mathrm{~N}\end{array}$ & $\epsilon-\mathrm{Fe}_{2-3} \mathrm{~N}$ & $\zeta-\mathrm{Fe}_{2} \mathrm{~N}$ \\
\hline $100^{\circ} \mathrm{C}$ & $\alpha-F e$ & $\begin{array}{l}\gamma^{\prime}-\mathrm{Fe}_{4} \mathrm{~N} \\
\epsilon-\mathrm{Fe}_{2-3} \mathrm{~N}\end{array}$ & $\begin{array}{l}\gamma^{\prime}-\mathrm{Fe}_{4} \mathrm{~N} \\
\epsilon-\mathrm{Fe}_{2-3} \mathrm{~N} \\
\text { Amorphous }\end{array}$ & $\epsilon-\mathrm{Fe}_{2-3} \mathrm{~N}$ & $\epsilon \cdot \mathrm{Fe}_{2-3} \mathrm{~N}$ & \\
\hline Unheated & $\alpha-\mathrm{Fe}$ & Amorphous & Amorphous & $\begin{array}{l}\text { Amorphous } \\
\epsilon-\mathrm{Fe}_{2-3} \mathrm{~N}\end{array}$ & $\epsilon-\mathrm{Fc}_{2-3} \mathrm{~N}$ & $\zeta-\mathrm{Fc}_{2} \mathrm{~N}$ \\
\hline${ }^{T}{ }_{x_{\mathrm{N}_{2}}}$ & 0.000 & 0.046 & 0.063 & 0.109 & 0.205 & 0.332 \\
\hline
\end{tabular}

(a)

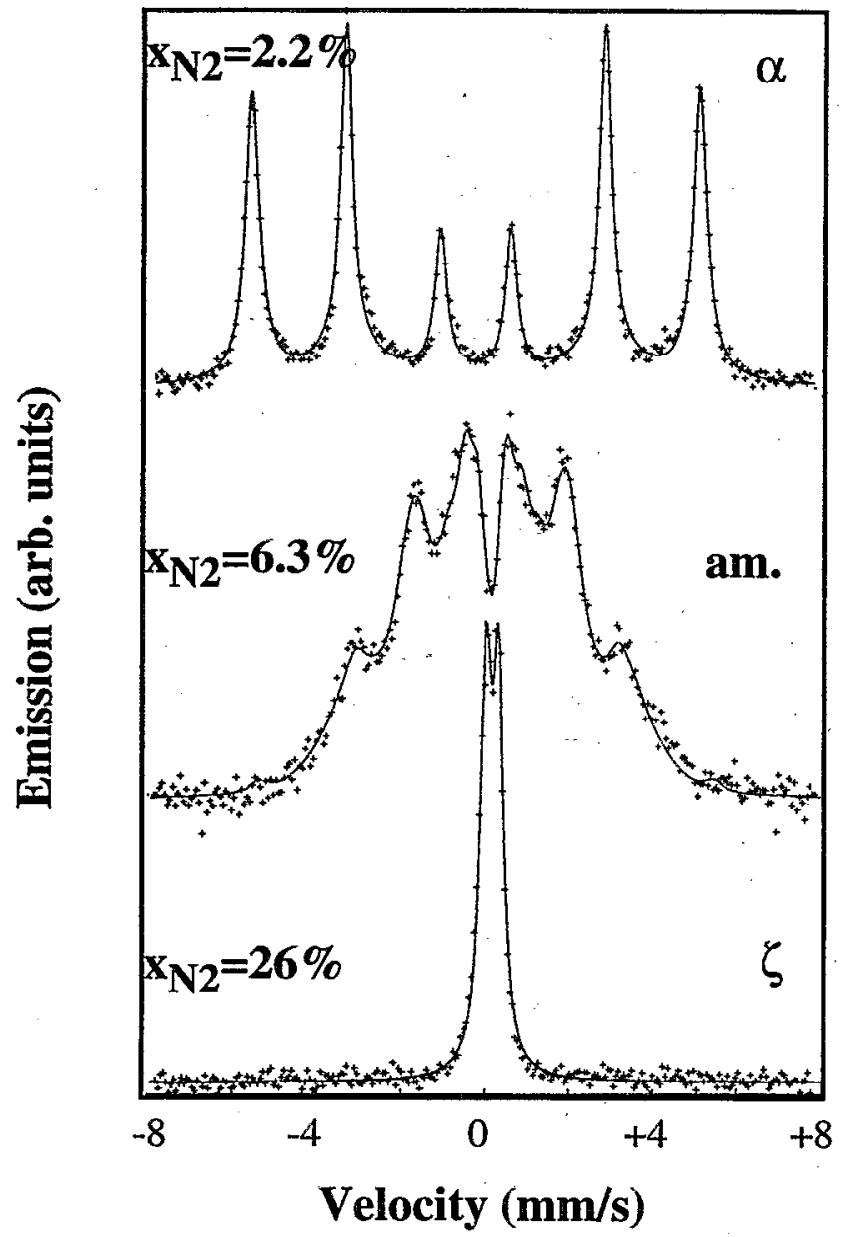

(b)

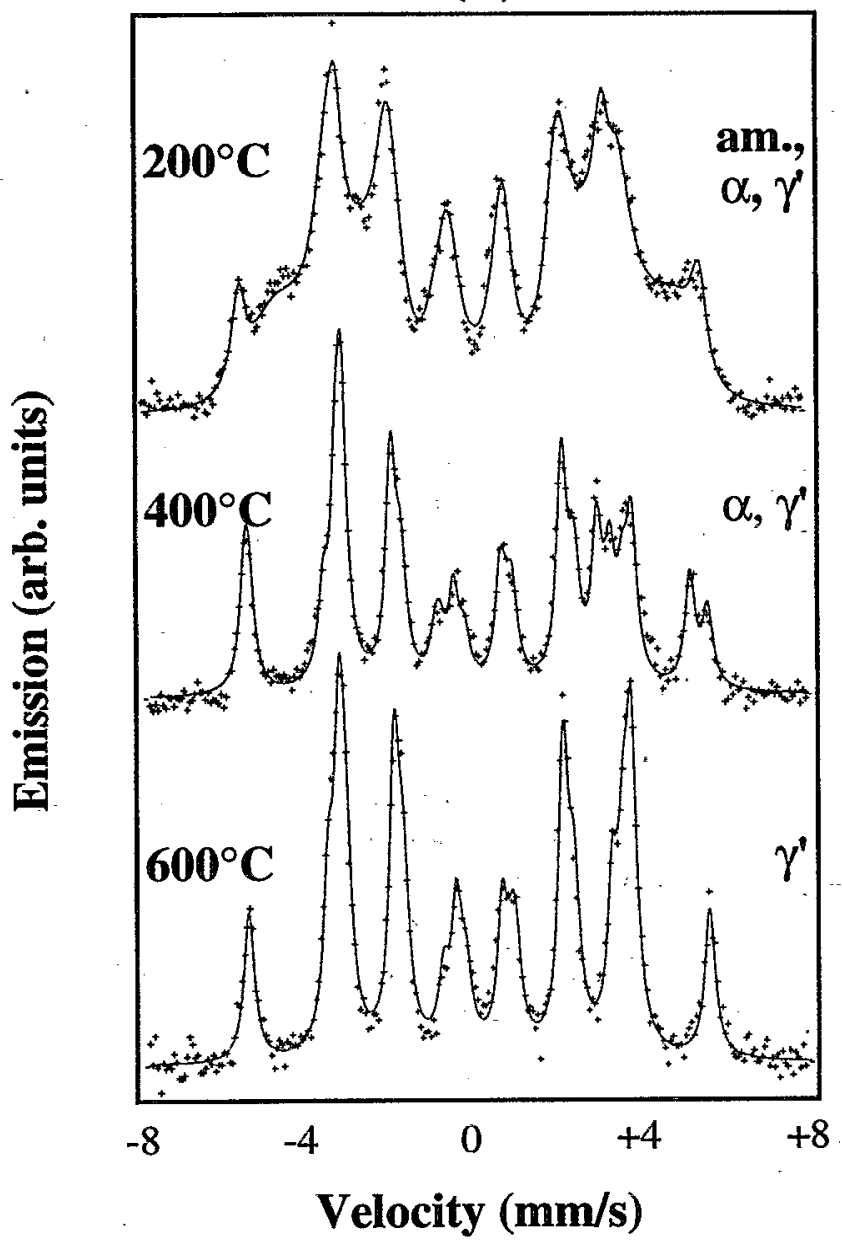

FIG. 2. CEMS spectra recorded for various preparation conditions of FeN films: (a) effect of increasing $x_{\mathrm{N}_{2}}$ for samples deposited on unheated substrates; (b) influence of substrate heating for $x_{\mathrm{N}_{2}}=6.3 \%$. The presence of $\alpha$-Fe, amorphous $\mathrm{Fe}_{1-x} \mathrm{~N}_{x}(\mathrm{am}), \gamma^{\prime}-\mathrm{Fe}_{4}-\mathrm{N}$, and $\zeta-\mathrm{Fe}_{2} \mathrm{~N}$ is evidenced. The nature of the different species are also reported in legends. 


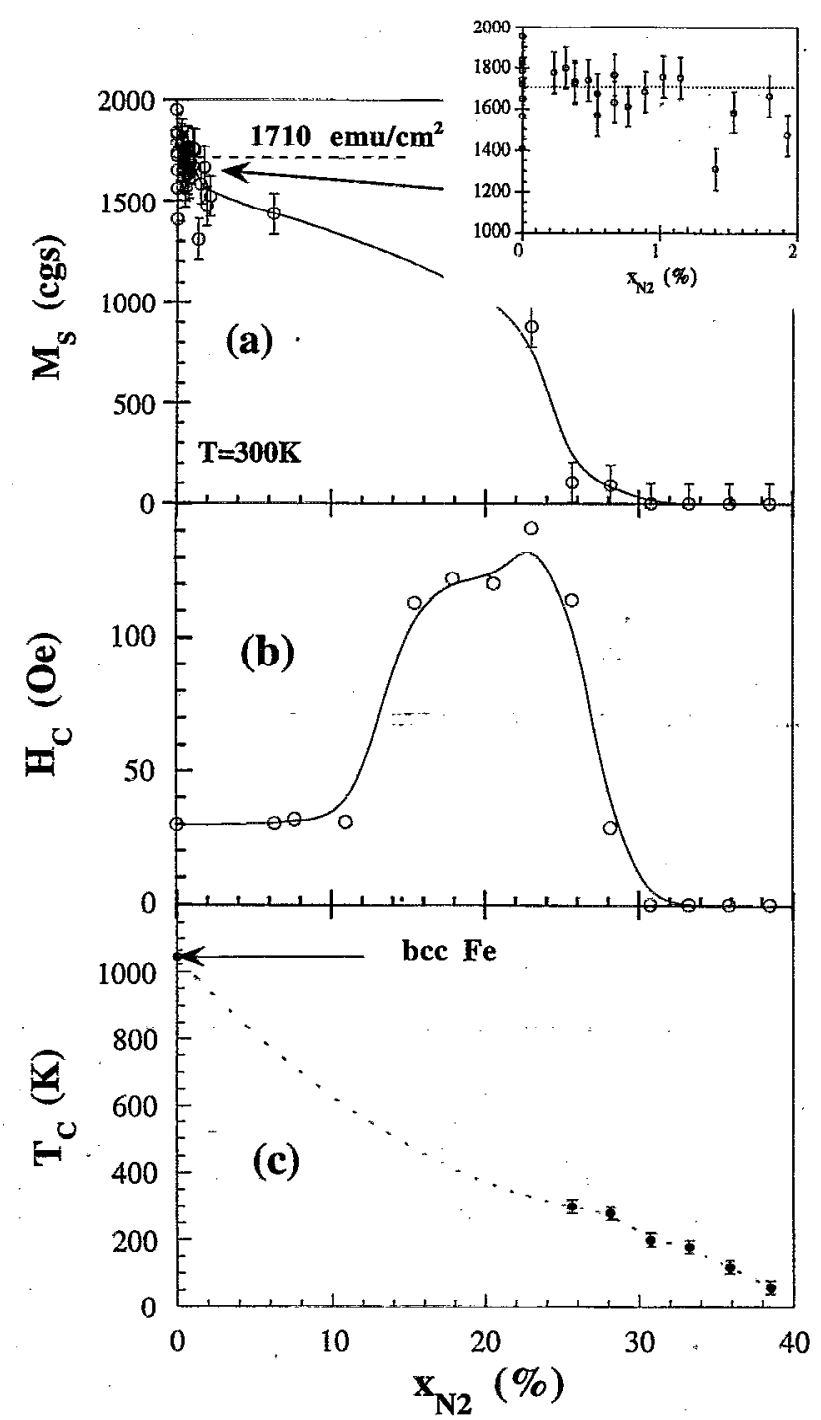

FTG. 3. Summary of the magnetic properties of Fe-N films prepared at room temperature as a function of the nitrogen to argon ratio $\left(x_{\mathrm{N}_{2}}\right)$ : (a) saturation magnetization at $300 \mathrm{~K}$, (b) coercive field at $300 \mathrm{~K}$, (c) Curie temperature (solid lines are only guides to the eye).

\section{Magnetic properties}

Concerning the magnetic properties of our samples, several studies have been performed: magnetic anisotropy, saturation magnetization at room temperature and, last, ferromagnetic fluctuations in $\zeta-\mathrm{Fe}_{2} \mathrm{~N}$ phase.

\section{Saturation magnetization versus $x_{N_{2}}$ of samples prepared at room temperature}

Figure 3(a) reports saturation magnetization $\left(M_{s}\right)$ dependence with $x_{\mathrm{N}_{2}}$. One clearly remarks the plateau at $\approx 1700 \mathrm{emu} / \mathrm{cm}^{3}$ for low $x_{\mathrm{N}_{2}}$. No enhancement of $M_{s}$ can be observed as confirmed by CEMS spectra which show the usual $330 \mathrm{kOe}$ hyperfine field sextet for these samples.

For increasing $x_{\mathrm{N}_{2}}, M_{s}$ starts to decrease. Room temperature saturation magnetization sharply decreases to zero values for $x_{\mathrm{N}_{2}}>0.24$, exactly when $\zeta-\mathrm{Fe}_{2} \mathrm{~N}$ is the only phase in our samples. Therefore, the $\zeta$ phase is found to be paramagnetic at room temperature by magnetization measurements and Mössbauer spectrometry.

\section{Magnetic anisotropy and coercivity of iron nitride films}

Hysteresis curves have been recorded for both in-plane and out-of-plane field geometries. In all the cases where nitrides are ferromagnetic (i.e., from $\alpha$-Fe to $\epsilon-\mathrm{Fe}_{3} \mathrm{~N}$ ), in-plane magnetization curves saturate at low fields while several kOe are necessary to saturate the out-of-plane ones. This field is found to decrease with the decrease of the saturation magnetization of the nitrides. It means that the origin of the magnetic anisotropy of our iron nitride films is essentially shape anisotropy.

Figure 3(b) shows the dependence with $x_{\mathrm{N}_{2}}$ of the coercive fields $\left(H_{c}\right)$ of iron nitride films deposited on unheated substrates. The increãse of $H_{c}$ up to 140 Oe for 0.18 $<x_{N_{2}}<0.24$ can be exactly correlated with the presence of $\epsilon-\mathrm{Fe}_{3} \mathrm{~N}$ which is well crystallized. For lower nitrogen concentrations, $H_{c}$ has low values $(\approx 30 \mathrm{Oe})$, it is coherent with the poor crystallization of the corresponding films. The coercive field of our sputtered iron nitrides is low in all cases

- and therefore compatible with magnetic recording requirements.

\section{Low temperature spin fluctuations in $\zeta-\mathrm{Fe}_{2} \mathrm{~N}$ films}

We have investigated low temperature magnetic behavior of iron nitride films prepared at room temperature with a nitrogen flow high enough for obtaining $\zeta-\mathrm{Fe}_{2} \mathrm{~N}\left(x_{\mathrm{N}_{2}}\right.$ $>0.24)$. Ferromagnetic fluctuations are characterized by $\mathrm{Ar}_{-}$ rott plots: $M^{2}(H, T)$ is plotted vs $H / M$ at various temperatures. These curves are expected to be linear in a mean field model. Curie temperature is deduced from the $H / M$ curve which passes by the origin. Such Arrott plots are presented in Fig. 4.

The good linear shape of these curves is a sign for the homogeneity of the samples. Our measurements show evidence for a decrease of the Curie temperature $T_{C}$ from $300 \mathrm{~K}$ for $x_{\mathrm{N}_{2}}=0.25$ down to $60 \mathrm{~K}$ for $x_{\mathrm{N}_{2}}=0.37$. These values are in agreement with those reported by Chen et al. ${ }^{10}$ for bulk $\zeta-\mathrm{Fe}_{2} \mathrm{~N}$ samples and their dependence versus $x_{\mathrm{N}_{2}}$ is shown in Fig. 3(c).

\section{DISCUSSION}

Our results shed light on the problem of preparing iron nitride films by reactive sputtering: the use of nitrogen in reactive gas mixture is a good solution to obtain all the various $\mathrm{Fe}-\mathrm{N}$ phases. We indicate the preparation conditions of single phase iron nitrides. Such phases can be obtained on unheated substrates except single phase $\gamma^{\prime}-\mathrm{Fe}_{4} \mathrm{~N}$ which requires substrate heating during sputtering.

Concerning the synthesis of $\alpha^{\prime \prime}-\mathrm{Fe}_{16} \mathrm{~N}_{2}$, we did not find in this batch of samples the conditions to obtain it. We did not either measure any enhancement of the saturation magnetization. However, we cannot conclude that $\alpha^{\prime \prime}-\mathrm{Fe}_{16} \mathrm{~N}_{2}$ has a larger $M_{s}$ than bulk iron. 


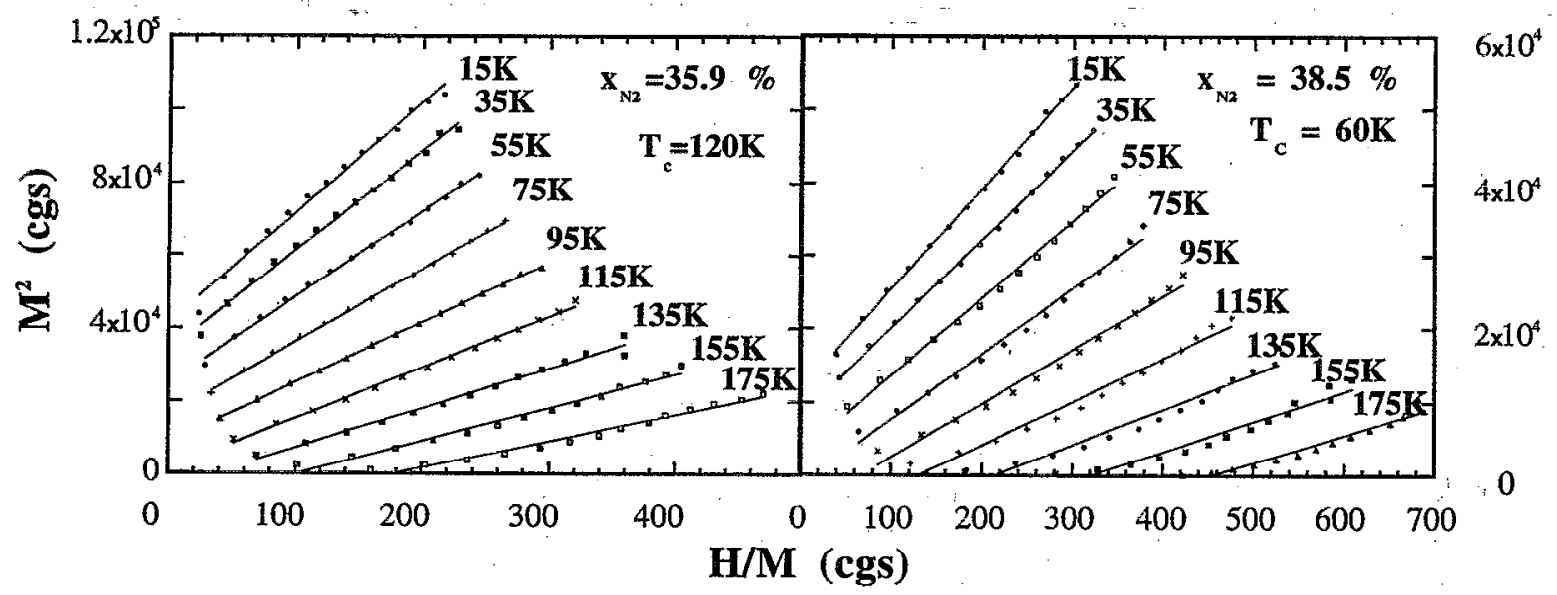

FIG. 4. Characterization of the ferromagnetic transition of samples with a stoichiometry close to $\zeta-\mathrm{Fe}_{2} \mathrm{~N}$ phase: Arrott plots.

One of the most original results of our study is that we have obtained amorphous $\mathrm{Fe}-\mathrm{N}$ alloy on unheated substrates. It presents a large saturation magnetization $(\sim \alpha \mathrm{Fe})$, soft magnetic properties (coercive field $\sim 25 \mathrm{Oe}$ ), and a rather large domain of existence versus the plasma composition (from $x_{\mathrm{N}_{2}} \approx 5 \%$ up to $20 \%$ ). This disordered phase transforms into $\mathrm{Fe}$ or $\mathrm{Fe}_{4} \mathrm{~N}$ when $T_{S}$ is increased. Let us also notice that success in preparation of this amorphous phase is related to the total thickness $t_{f}$ of the films: for $t_{f}>5000 \AA$, amorphous iron nitride tends to transform into $\mathrm{Fe}$ or $\mathrm{Fe}_{4} \mathrm{~N}$ as well as for heated substrates. This behavior is attributed to a plasma heating of the substrates during the deposition duration $(\approx 1-5 \mathrm{~h})$.

Concerning low nitrogen concentrations, the $\alpha$ Fe- $N$ phase presents a non-negligible lattice expansion. From naive band structure considerations; we would expect an enhanced magnetization in such a nitride compared to pure iron. We do not find any increase of $M_{S}$, so it proves that a structural expansion of iron nitride structure is not enough for an increase of magnetization.

\section{CONCLUSION}

Using a conventional argon-nitrogen gaseous mixture, we have been able to produce iron nitride films in a large range of atomic concentrations and equilibrium phases: $\mathrm{Fe}$,
$\mathrm{Fe}_{4} \mathrm{~N}, \mathrm{Fe}_{2-3} \mathrm{~N}, \mathrm{Fe}_{2} \mathrm{~N}$. By varying the stoichiometry of $\mathrm{Fe}_{2} \mathrm{~N}$, we could control the Curie temperature of the films between room temperature and $60 \mathrm{~K}$. These preparation conditions have even allowed us to obtain expanded $\alpha \mathrm{Fe}-\mathrm{N}$ and a new amorphous iron nitride with soft magnetic properties. Further, these results show that an increase of the lattice parameter is not sufficient for the stabilization of a higher spin material. Other effects related for instance to local order could play a crucial role.

'S. F: Matar, G. Demazeau, and B. Siberchicot, IFFF, Trans. Magn. MAG26, 60 (1990).

${ }^{2}$ T. K. Kim and M. Takahashi, Appl. Phys. Lett. 20, 492 (1972).

${ }^{3}$ M. Takahashi, H. Shoji, and M. Tsunod, J. Magñ. Magn. Mater. 134, 403 (1994).

${ }^{4} \mathrm{M}$. Vergnat, H. Chatbi, Ph. Bauer, and G. Marchal (private communica(ion).

${ }^{5}$ M. Komuro, Y. Kozono, M. Hanazono, and Y. Sugita, J. Appl. Phys. 60, 5126 (1990); Y. Sugita, M. Mitsuoka, M. Komuro, H. Yoshiya, Y. Kozono, and M. Hanazono, ibid. 70, 5977 (1991).

${ }^{6}$ M. Takahashi, H. Shoji, H. Takahashi, T. Wakiyama, M. Kinoshita, and W. Ohta, IEEE Trans. Magn. MAG-29, 3040 (1993).

${ }^{7} \mathrm{C}$. Gao and M. Shamsuzzoha, IEEE Trans. Magn. MAG-29, 3046 (1993).

${ }^{8}$ J. Q. Xiao and C. L. Chien, Appl. Phys. Lett. 64, 384 (1994).

${ }^{9}$ Such iron films have been successfully used as seed layers for $\mathrm{Cu}-\mathrm{Co}$ multilayers which exhibited large giant magnetoresistance values. See, for example, J.-F. Bobo, B. Baylac, L. Hennet, O. Lenoble, M. Piecuch, B: Raquet, and J.-C. Ousset, J. Magn. Magn. Mater. 121, 291 (1993).

${ }^{10}$ G. M. Chen, M. X. Lin, and J. W. Ling, J. Appl. Phys. 75, 6293 (1994). 